\title{
PENGARUH PENDAPATAN DAN GAYA HIDUP \\ TERHADAP TINGKAT KONSUMSI MAHASISWA SEMESTER VI TAHUN AKADEMIK 2018-2019 SEKOLAH TINGGI ILMU EKONOMI INDRAGIRI (STIE-I) RENGAT
}

\author{
Oleh: \\ ARIS TRIYONO ${ }^{1)}$ SAID AFRIARIS ${ }^{2)}$ \\ ${ }^{1)}$ Program Studi Manajemen, Sekolah Tinggi Ilmu Ekonomi Indragiri (STIE-I) Rengat \\ Email: arist@stieindragiri.ac.id \\ ${ }^{2)}$ Program Studi Manajemen, Sekolah Tinggi Ilmu Ekonomi Indragiri (STIE-I) Rengat \\ Email: saidafriaris@stieindragiri.ac.id
}

\begin{abstract}
This research aims to determine the effect of income and lifestyle on consumer behavior in students. This type of research is quantitative descriptive research. The total population is 379 with random sampling technique, a sample of 114 respondents was taken. While the data analysis technique used is the analysis of multiple linear regression and analysis (R2) amounting to 0.781 which means 78,\% consumption behavior is influenced by income and lifestyle, While the remaining $22 \%$ is influenced by other independent variables not examined in this study. Therefore, for further research in order to be able to add other variables besides the two independent variables in this study and be wise consumers who are able to distinguish between wants and needs.
\end{abstract}

Keywords: Income, Lifestyle, Consumptive

\begin{abstract}
Abstrak
Penelitian ini bertujuan untuk mengetahui pengaruh pendapatan dan gaya hidup terhadap perilaku konsumtif pada Mahasiswa. Jenis penelitian ini adalah penelitian deskriptif kuantitatif. Jumlah Populasi sebanyak 379 dengan teknik pengambilan sampel random sampling, diambil sampel berjumlah 114 responden. Sedangkan teknik analisa data yang digunakan adalah analisis regresi linier berganda dan analisis (R2), sebesar 0,781 yang artinya 78,\% perilaku konsumsi dipengaruhi oleh pendapatan dan gaya hidup. Sedangkan sisanya $22 \%$ dipengaruhi oleh variabel bebas lain yang tidak diteliti dalam penelitian ini. Oleh sebab itu, bagi penelitian selanjutnya agar dapat menambahkan variabel lain selain kedua variabel bebas dalam penelitian ini dan jadilah konsumen yang bijaksana yang mampu membedakan antara keinginan dan kebutuhan.
\end{abstract}

Kata Kunci : Pendapatan, Gaya Hidup, Tingkat Konsumsi

\section{PENDAHULUAN}

Dalam kehidupan sehari-hari manusia selalu terus berusaha untuk memenuhi kebutuhan, karena pada dasarnya manusia tidak lepas dari kebutuhan dan tidak akan pernah puas, kebutuhan dapat terpenuhi salah satunya dengan kegiatan konsumsi, dimana konsumen akan mengalokasikan kekayaan yang dimilikinya untuk memenuhi kebutuhan, hal ini juga berdampak pada pola konsumtif bagi mahasiswa di kalangan kampus, salah satu kampus yang terfaforit di Kabupaten Indragiri Hulu, Sekolah Tinggi Ilmu Ekonomi Indragiri (STIE-I) Rengat. berdasarkan pengamatan penulis, mahasiswa STIE-I Rengat, tergolong kunsumtif. Dimana para mahasiswa lebih sering membeli barang-barang di pusat perbelanjaan modern dari pada pasar tradisional. Penelitian ini melakukan wawancara pada 8 orang, mahasiswa semester VI (enam) secara langsung, adapun hasil wawancara tersebut dapat dilihat pada tabel di bawah ini: 
Tabel 1 : Hasil wawancara Tingkat konsumsi mahasiswa STIE-I Rengat Semester VI TA.2018-2019

\begin{tabular}{|l|l|c|c|c|r|}
\hline No & \multicolumn{1}{|c|}{ Nama } & Konsentasi & Usia & L/P & $\begin{array}{c}\text { Tingkat } \\
\text { Kunsumsi }\end{array}$ \\
\hline 1 & Juri An Nissa & Sdm & 21 & $\mathrm{P}$ & 2.000 .000$. \\
\hline 2 & Ayu Isma Lestari & Sdm & 26 & $\mathrm{P}$ & 1.500 .000$. \\
\hline 3 & Rofi afriandi & Keuangan & 24 & $\mathrm{~L}$ & 1.000 .000$. \\
\hline 4 & Dewi lestari & Keuangan & 23 & $\mathrm{P}$ & 300.000. \\
\hline 5 & Yuni azzarohi & $\mathrm{Kwr}$ & 23 & $\mathrm{P}$ & 2.000 .000$. \\
\hline 6 & Ambrizal & $\mathrm{Kwr}$ & 21 & $\mathrm{~L}$ & 1.000 .000$. \\
\hline 7 & Windi saputra & $\mathrm{Mpd}$ & 21 & $\mathrm{~L}$ & 800.000. \\
\hline 8 & Nurita sarah & $\mathrm{Mpd}$ & 21 & $\mathrm{P}$ & 2.000 .000$. \\
\hline
\end{tabular}

Sumber : Wawancara (data diolah peneliti, 2019)

Dari tabel hasil wawancara diatas, bahwa tingkat konsumsi mahasiswa STIE-Indragiri Rengat, sangat bervariasi, ada beberapa factor yang mempengaruhi tingkat konsumsi seseorang diantaranya faktor pendapatan dan gaya hidup.

Pendapatan mahasiswa STIE-Indragiri Rengat berdasarkan hasil wawancara penulis dengan mahasiswa adalah sebagai berikut;

Tabel 2 : Hasil wawancara Pendapatn mahasiswa STIE-I Rengat Semester VI TA.2018-2019

\begin{tabular}{|l|l|c|c|c|r|}
\hline No & \multicolumn{1}{|c|}{ Nama } & Konsentasi & Usia & L/P & Pendapatan \\
\hline 1 & Juri An Nissa & Sdm & 21 & $\mathrm{P}$ & 1.500 .000$. \\
\hline 2 & Ayu Isma Lestari & Sdm & 26 & $\mathrm{P}$ & 2.000 .000$. \\
\hline 3 & Rofi afriandi & Keuangan & 24 & $\mathrm{~L}$ & 2.500 .000$. \\
\hline 4 & Dewi lestari & Keuangan & 23 & $\mathrm{P}$ & 700.000. \\
\hline 5 & Yuni azzarohi & Kwr & 23 & $\mathrm{P}$ & 2.000 .000$. \\
\hline 6 & Ambrizal & Kwr & 21 & $\mathrm{~L}$ & 2.000 .000$. \\
\hline 7 & Windi saputra & $\mathrm{Mpd}$ & 21 & $\mathrm{~L}$ & 2.000 .000$. \\
\hline 8 & Nurita sarah & $\mathrm{Mpd}$ & 21 & $\mathrm{P}$ & 2.500 .000$. \\
\hline
\end{tabular}

Sumber : Wawancara (data diolah peneliti, 2019)

Dari tabel hasil wawancara diatas, pendapatan mahasiswa STIE-Indragiri Rengat, berasal dari orang tua, bekerja dan beasiswa yang didapat oleh mahasiswa dalam satu bulan.

“Kotler (2002;192)”. Pola hidup seseorang di dunia yang diekspresikan dalam aktivitas, minat, dan opininya. Gaya hidup menggambarkan keseluruhan diri seseorang dalam berinteraksi dengan lingkungannya. Dimana gaya hidup mewah dapat di artikan dengan gaya hidup konsumtif (consumptive) adalah boros atau perilaku boros yang mengkonsumsi barang atau jasa secara berlebihan atau bukan atas dasar kebutuhan. Gaya hidup konsumtif menurut (Pratiwi, 2012) yaitu meliputi seluruh kelompok masyarakat termasuk diantaranya mahasiswa.

Gaya hidup sederhana merupakan gaya hidup yang tidak melebihi tingkat pendapatan, menurut (Al-Muhasibi, 2006) hidup sederhana berarti membebaskan segala ikatan yang tidak diperlukan, berbeda dengan kemiskinan, kesederhanaan merupakan suatu pilihan, keputusan untuk menjalani hidup yang berfokus pada apa yang benar-benar berarti gaya hidup untuk kalangan mahsiswa STIE-Indragiri 
Rengat berdasarkan hasil pengamatan secara langsung pada beberapa mahasiswa dapat di lihat pada tabel berikut;

Tabel 3 : Hasil pengamatan Gaya hidup pada mahasiswa STIE-I Rengat Semester VI TA.2018-2019

\begin{tabular}{|l|l|c|c|c|c|c|}
\hline No & \multicolumn{1}{|c|}{ Nama } & Konsentasi & Usia & \multirow{2}{*}{ L/P } & \multicolumn{2}{|c|}{ Gaya Hidup } \\
\cline { 6 - 8 } & & & & & Sederhana & Mewah \\
\hline 1 & Juri An Nissa & Sdm & 21 & P & Sederhana & \\
\hline 2 & Ayu Isma Lestari & Sdm & 26 & P & & Mewah \\
\hline 3 & Rofi afriandi & Keuangan & 24 & L & & Mewah \\
\hline 4 & Dewi lestari & Keuangan & 23 & P & Sederhana & \\
\hline 5 & Yuni azzarohi & Kwr & 23 & P & & Mewah \\
\hline 6 & Ambrizal & Kwr & 21 & L & Sederhana & \\
\hline 7 & Windi saputra & Mpd & 21 & L & Sederhana & \\
\hline 8 & Nurita sarah & Mpd & 21 & P & & Mewah \\
\hline
\end{tabular}

Sumber : Pengamatan (data diolah peneliti, 2019)

Tabel hasil pengamatan langsun tentang gaya hidup mahasiswa STIEIndragiri Rengat beragam, hal ini disebabkan oleh beberapa faktor diantaranya pendapatan dan tingkat konsumtif mahasiswa yang bersangkutan. Penelitian oleh Hasnira (2017) hasil penelitian dilihat bahwa pendapatan dan gaya hidup berpengaruh positif dan signifikan terhadap konsumsi masyarakat.

Berdasarkan hasil wawancara, pengamatan, fenomena, dan uraian teoritis serta penelitian sebelumnya, dapat diambil judul penelitian yaitu ; "Pengaruh Pendapatan dan Gaya Hidup Terhadap Tingkat Konsumsi Mahasiwa Semester VI. Ta. 2018-2019. Sekolah Tinggi Ilmu Ekonomi Indragiri (STIE-I) Rengat”.

\section{Rumusan Masalah}

1. Bagaimana pengaruh pendapatan terhadap tingkat konsumsi mahasiswa Semester VI. TA. 2018-2019. Sekolah Tinggi Ilmu Ekonomi Indragiri (STIEI) Rengat?

2. Bagaimana pengaruh gaya hidup terhadap tingkat konsumsi mahasiswa Semester VI. TA. 2018-2019 Sekolah Tinggi Ilmu Ekonomi Indragiri (STIEI) Rengat?

\section{TINJAUAN PUSTAKA}

\section{A. Konsumsi}

Konsumsi secara umum dapat diartikan sebagai pengguna barang dan jasa secara langsung akan memenuhi kebutuhan manusia (Suherman Rosyidi, 2011: 163). Dengan adanya lapisan masyarakat yang berbeda, tujuam konsumsi juga berbeda. Masyarakat tradisional yang ditandai dengan peradaban belum maju serta dengan kebutuhan yang masih sederhana untuk memenuhi kebutuhan sehari-hari

Menurut James F. Engel, dkk. (2015) Gaya hidup adalah cara hidup seseorang yang menghabiskan waktu dan daya guna uang. Sutanti (2011) mengungkapkan bahwa seseorang yang menyukai gaya hidup yang mewah maka perilaku yang mewah maka tingkat konsumsinya tinggi.

Menurut Mankiw (2013:311), mengatakan bahwa konsumsi adalah suatu barang pembelanjaan rumah tangga untuk barang dan jasa. "Barang" meliputi 
pembelanjaan rumah tangga untuk barang awet, seperti mobil, alat-alat rumah tangga, serta barang tidak awet berupa makanan dan pakaian, "jasa" meliputi barang-barang tidak kasat mata, seperti layanan kesehatan. Pembelanjaan rumah tangga untuk pendidikan termasuk kedalam konsumsi jasa.

Muhamad Abdul Halim, (2012:47) mengatakan bahwa Pengeluaran konsumsi rumah tangga merupakan Pengeluaran yang dilakukan oleh rumah tangga untuk membeli barang dan jasa untuk kebutuhan hidup sehari-hari dalam suatu periode tertentu. Menurut Tobing (2015:5), bahwa pola konsumsi merupakan gambaran alokasi dan komposisi atau suatu bentuk konsumsi yang berlaku secara umum. Konsumsi dapat diartikan sebagai kegiatan pemenuhan kebutuhan saat ini untuk meningkatkan kesejahteraan.

\section{B. Pendapatan}

Sadono Sukirno, (2011:108) mengemukakan bahwa Pendapatan rumah tangga menentukan tingkat konsumsi secara seunit kecil atau dalam keseluruhan ekonomi. Reksoprayitno mengemukakan bahwa pendapatan sebagai total penerimaan yang diperoleh pada periode tertentu (Mahyu Danil, 2013:37).

Menurut Sadono Sukirno (2011: 109) ciri hubungan antara pengeluaran konsumsi dan pendapatan disposabel yaitu:

1) Pada pendapatan yang rendah rumah tangga mengorek tabungan, apabila rumah tangga tidak memperoleh pendapatan, yaitu pendapatan disposabel adalah nol, maka rumah tangga harus menggunakan harta atau tabungan masa lalu untuk biaya pengeluaran konsumsinya.

2. Kenaikkan pendapatan menaikkan pengeluaran konsumsi. Biasanya pertambahan pendapatan adalah lebih tinggi daripada pertambahan konsumsi. Sisa pertambahan pendapatan tersebut ditabung.

3. Pada pendapatan yang tinggi rumah tangga menabung. Disebabkan pertambahan pendapatan selalu lebih besar dari pertambahan konsumsi maka pada akhirnya rumah tangga tidak "mengorek tabungan" lagi. Ia akan mampu menabung sebagian dari pendapatannya.

\section{Gaya Hidup}

Armstrong menyatakan bahwa faktor-faktor yang mempengaruhi gaya hidup seseorang ada 2 faktor yaitu faktor yang berasal dari dalam diri individu seseorang (internal) dan faktor yang berasal dari luar (eksternal) (Angga Sandy Susanto, 2013: 1-3)

Ujang Suwarman (2004: 67), mengungkapkan bahwa gaya hidup merupakan konsep yang lebih baru dan lebih muda terukur dibandingkan denga sikap.

Menurut Ristiayanti dan Ihalauw (2006:56) mendefinisikan bahwa gaya hidup sebagaimana orang hidup, termasuk bagaimana menggunakan uang, dan bagaimana seseorang mengalokasi waktu.

Sumartono mengungkap beberapa perilaku konsumtif (Sukari, dkk, 2013:1617) yaitu dimana seseorang membeli produk karna hadiah, kemasan menarik, penampilan dan gengsi, atas pertimbangan harga ( bukan atas dasar manfaat atau kegunaan ), membeli produk hanya sekedar menjaga symbol status, karena unsur konformitas terhadap model yang menngiklankan, adanya penilaian bahwa 
membeli produk mahal akan menimbulkan rasa percaya diri, serta mencoba lebih dari dua produk sejenis dengan merek berbeda.

\section{Penelitian Terdahulu}

1. Sutriati, Sri Kartikowati, RM Riadi (2018) dalam penelitiannya yang berjudul "Pengaruh Pendapatan Dan Gaya Hidup Terhadap Perilaku Konsumtif Pada Mahasiswa Jurusan Pendidikan Ilmu Pengetahuan Social Fkip Universitas Riau”. Adapun tujuan penelitian ini adalah untuk mengetahui pengaruh pendapatan dan gaya hidup terhadap perilaku konsumtif pada Mah asiswa Jurusan Pendidikan Ilmu Pengetahun Sosial Angkatan 2015 Fakultas Keguruan dan Ilmu Pendidikan Universitas Riau. Jenis penelitian ini adalah penelitian deskriptif kuantitatif. Populasi dalam penelitian ini berjumlah 220 responden. Dengan menggunakan teknik pengambilan sampel random sampling, diambil sampel sejumlah 126 responden. Sedangkan teknik analisa data yang digunakan adalah analisis regresi berganda dan analisis R. Pengujianhipotesis dilakukan dengan uji siginifikan parsial dan uji signifikan simultan. Berdasarkan hasil penelitian diperoleh bahwa nilai koefisien determinasi (R) sebesar $54,2 \%$ yang artinya $54,2 \%$ perilaku konsumtif dipengaruhi oleh pendapatan dan gaya hidup sedangkan sisanya $45,8 \%$ dipengaruhi oleh variabel bebas lain yang tidak termasuk dalam penelitian.

2. Hasnira (2017) Dalam penelitiannya yang berjudul "Pengaruh Pendapatan dan Gaya Hidup Terhadap Pola Konsumsi Masyarakat Wahdah Islamiyah Makassar" Penelitian ini termasuk jenis penelitian deskriptif kuantitatif. Populasi dalam penelitian ini yaitu masyarakat Wahdah Islamiyah Makassar yang mempunyai pendapatan tetap dan telah bekerja tiga tahun ke atas. Dengan menggunakan teknik pengambilan sampel menggunakan rumus Slovin, jumlah sampel dalam penelitian ini berjumlah 100 orang. Hasil penelitian menunjukkan bahwa pendapatan dan gaya hidup berpengaruh positif dan signifikan terhadapa konsumsi masyarakat Wahdah Islamiyah Makassar. Namun variabel pendapatan memiliki pengaruh paling dominan terhadap konsumsi masyarakat Wahdah Islamiyah Makassar. Dari hasil regresi, koefisien kolerasi $(\mathrm{R})$ menunjukkan bahwa variabel bebas (pendapatan dan gaya hidup) memiliki hubungan yang erat dengan variabel terikat (konsumsi masyarakat), sedangkan koefisien determinasi ( $\left.\mathrm{R}_{2}\right)$ menunjukan adanya pengaruh yang besar antara variabel bebas dengan variabel terikat.

\section{Kerangka Pemikiran}

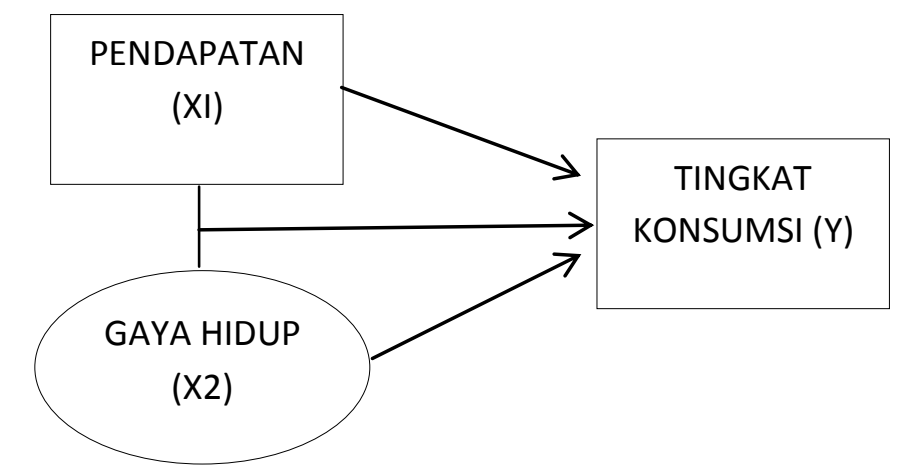

Gambar 1. Kerangka Penelitian 


\section{Volume VIII, No. 01, September 2019}

\section{Hipotesis Penelitian}

1. Pendapatan berpengaruh positif dan signifikan terhadap tingkat konsumsi mahasiswa.

2. Gaya hidup berpengaruh positif dan signifikan terhadap tingkat konsumsi mahasiswa.

3. Pendapatan dan gaya hidup, berpengaruh signifikan terhadap tingkat konsumsi mahasiswa.

\section{METODE PENELITIAN}

Penelitian ini dilakukan di Sekolah Tinggi Ilmu Ekonomi Indragiri (STIE-I) Rengat. Populasi penelitian seluruh mahasiswa Sekolah Sekolah Tinggi Ilmu Ekonomi Indragiri (STIE-I) Rengat Tahun akademik 2018-2019 semester VI. Dengan jumlah 370 Mahasiswa sebagai sampel 114 mahasiswa dengan teknik Proporsional Random Sampling. Metode pengumpulan data kuesioner, dokumentasi, wawancara dan Analisis data terdiri dari Analisis Deskriptif dan Analisis Inferensial, Uji Prasyarat Analisis dan analisisi regresi linier berganda, dengan menggunakan aplikasi SPSS 21.

\section{HASIL DAN PEMBAHASAN}

\section{Analisis Depkriptif Variabel}

a. Variabel Pendapatan

Adapaun hasil penyebaran kuisioner variabel Pendapatan sebagai berikut;

Tabel, 4 Kategorisasi Variabel Pendapatan

\begin{tabular}{|c|c|c|c|}
\hline Kategori & \multicolumn{1}{|c|}{ Pendapatan (Rp) } & $\begin{array}{c}\text { Banyaknya } \\
\text { Responden }\end{array}$ & $\begin{array}{c}\text { Presentase } \\
(\%)\end{array}$ \\
\hline Rendah & $300.000 .-800.000$. & 55 & $49 \%$ \\
\hline Cukup & $805.000 .-1.000 .000$. & 28 & $24 \%$ \\
\hline Tinggi & $1.100 .000 .-2.000 .000$. & 29 & $25 \%$ \\
\hline Sangat Tinggi & $2.100 .000 .-5.000 .000$. & 2 & $2 \%$ \\
\hline Total & & 114 & $100 . \%$ \\
\hline
\end{tabular}

Sumber : Data Primer yang diolah, 2019.

Dari tabel di atas dapat dijelaskan bahwa dari 114 responden, kategori rendah sebanyak 55 orang (49\%), kategori cukup sebanyak 28 orang (24\%), kategori tinggi sebanyak 28 orang (25\%). Dimana kategori sangat tinggi sebanyak 2 orang (2\%), sehingga dapat disimpulkan bahwa sebagian besar responden mempunyai pendapatan dengan kategori rendah yaitu sebanyak 55 orang (49\%).

b. Variabel Gaya hidup

Adapaun hasil penyebaran kuisioner variabel Gaya hidup sebagai berikut;

Tabel, 5 Kategorisasi Variabel Gaya hidup.

\begin{tabular}{|c|c|c|c|}
\hline Kategori & $\begin{array}{c}\text { Gaya hidup } \\
\text { (dammy) }\end{array}$ & $\begin{array}{c}\text { Banyaknya } \\
\text { Responden }\end{array}$ & $\begin{array}{c}\text { Presentase } \\
(\%)\end{array}$ \\
\hline Sederhana & 1 & 67 & $59 \%$ \\
\hline Mewah & 2 & 47 & $41 \%$ \\
\hline Total & & 114 & $100 \%$ \\
\hline
\end{tabular}

Sumber : Data Primer yang diolah, 2019. 
Hasil tabel di atas menunjukkan bahwa, dari 114 responden, bahwa gaya hidup sederhana sebanyak 67 responden dan presentase 59\%, sedangkan $41 \%$, dengan kategori hidup mewah, berarti mahasiswa STIE-I Rengat dalam hal Gaya hidup di kategorikan sederhana atau rendah.

c. Variabel Tingkat konsumsi

Adapun hasil penyebaran kuisioner variable Tingkat Konsumsi sebagai berikut: Tabel, 6 Skala data Tingkat konsumsi

\begin{tabular}{|c|c|c|c|}
\hline Kategori & $\begin{array}{c}\text { Tingkat konsumsi } \\
(\mathrm{Rp})\end{array}$ & $\begin{array}{c}\text { Banyaknya } \\
\text { Responden }\end{array}$ & $\begin{array}{c}\text { Presentase } \\
(\%)\end{array}$ \\
\hline Rendah & $300.000 .-800.000$. & 77 & $68 \%$ \\
\hline Cukup & $805.000 .-1.000 .000$. & 21 & $18 \%$ \\
\hline Tinggi & $1.100 .000 .-2.000 .000$. & 15 & $13 \%$ \\
\hline Sangat tinggi & $2.100 .000 .-5.000 .000$. & 1 & $1 \%$ \\
\hline Total & & 114 & 100 \\
\hline
\end{tabular}

Sumber : Data Primer yang diolah, 2019.

Dari tabel di atas dapat dijelaskan bahwa dari 114 responden, 1 orang (1\%) dengan tingkat konsumsi kategori sangat tinggi, kategori rendah sebanyak 77 orang (68\%), kategori cukup yaitu sebanyak 21 orang (18\%), dan dengan kategori tinggi sebanyak 15 orang atau sebesar (13\%). Sehingga dapat disimpulkan bahwa sebagian besar dari responden mempunyai tingkat konsumsi dengan kategori rendah yaitu sebanyak 77 orang, atau sebesar $(68 \%)$.

\section{Hasil Penelitian Uji Asumsi Klasik}

a. Uji Normalitas

Dari hasil Uji Normalitas dapat dijelaskan bahwa nilai Asymp, Sig.(2tailed) yaitu lebih dari 0,05 maka dapat disimpulkan bahwa residual terdistribusi normal.

b. Uji Autokorelasi

Hasil dari Uji Aitokorelasi menunjukan bahwa pada kotak Runs Test terlihat nilai Asymp. Sig.(2-tailed) hitung sebesar 0,257 sehingga diputuskan bahwa tidak terdapat autokorelasi dalam model regresi.

b. Uji Multikolinearitas

Dari hasil Uji Multikolinearitas menghasilkan bahwa nilai VIF kurang dari 4 maka dapat disimpulkan bahwa tidak terjadi multikolinearitas antar variabel bebas.

\section{Hasil Analisis Data}

a. Analisis Regresi Linier Berganda

Berdasarkan hasil uji regresi berganda melalui pengalahan data menggunakan SPSS 21.

Tabel : 10. Hasil Uji Analisis Linier Berganda

\begin{tabular}{|c|c|c|c|c|c|c|}
\hline \multirow{3}{*}{\multicolumn{2}{|c|}{ Model }} & \multicolumn{4}{|c|}{ Coefficients ${ }^{*}$} & \multirow{3}{*}{ Sig. } \\
\hline & & \multicolumn{2}{|c|}{ Unstandardized Coefficients } & \multirow{2}{*}{$\begin{array}{c}\text { Standardized } \\
\text { Coefficients } \\
\text { Beta } \\
\end{array}$} & \multirow[t]{2}{*}{$t$} & \\
\hline & & $\mathrm{B}$ & Std. Error & & & \\
\hline \multirow{3}{*}{1} & (Constant) & .119 & .058 & & 2.060 & .042 \\
\hline & $\mathrm{X} 1$ & .626 & .032 & .871 & 19.340 & .000 \\
\hline & $x 2$ & .050 & .073 & .061 & 1.349 & .001 \\
\hline
\end{tabular}


Dari hasil perhitungan tabel diatas, maka dibentuk persamaan regresi berganda sebagai berikut : $Y=0,119+0,626 X_{1}+0,050$

Dengan variabel $\mathrm{X}_{1}$ adalah Pendapatan, variabel $\mathrm{X}_{2}$ adalah Gaya hidup dan variabel $\mathrm{Y}$ adalah Tingkat konsumsi.

Adapun interpretasi dari model regresi di muka adalah : $\mathrm{a}=0,119$.

Jika Pendapatan dan gaya hidup sama dengan nol (0) maka besarnya tingkat konsumsi sebesar 0,119 poin. $\mathrm{b} 1=0,626$

Jika pendapatn meningkat 1 (satu) satuan (sementara gaya hidup tetap) maka tingkat konsumsi mengalami peningkatan sebesar 0,626 poin. $\mathrm{b} 2=0,050$.

Jika pendapatan meningkat sebesar 1 (satu) satuan (sementara gaya hidup tetap) maka tingkat konsumsi akan mengalami peningkatan sebesar 0,050 poin.

b. Uji F

Tabel, 11 Hasil Uji F (Simultan)

\begin{tabular}{|c|c|c|c|c|c|c|}
\hline \multicolumn{7}{|c|}{ ANOYA: } \\
\hline Model & & Sum of Squares & $\mathrm{df}$ & Mean Square & $\mathrm{F}$ & Sig. \\
\hline & Regression & 14.725 & 2 & 7.362 & 202.996 & $.000^{\circ}$ \\
\hline 1 & Residual & 4.026 & 111 & .036 & & \\
\hline & Total & 18.751 & 113 & & & \\
\hline
\end{tabular}

a. Dependent Variable: $Y$

b. Predictors: (Constant), X2, X1

Dilihat dari table diatas hasil perhitungan Uji F, bahwa nilai Sig $=$ 0,000 dengan nilai $F$ hitung sebesar 202,996 dan nilai $F$ tabel sebesar 3,08 , hasil penelitian ini menunjukan bahwa F hitung $(202,996)>F$ tabel $(3,08)$, artinya Pendapatan dan Gaya hidup secara bersama-sama berpengaruh signifikan terhadap Tingkat konsumsi.

c. Uji t

Tabel, 12. Hasil Uji t

\begin{tabular}{|c|c|c|c|c|c|c|}
\hline \multirow{3}{*}{\multicolumn{2}{|c|}{ Model }} & \multicolumn{3}{|c|}{ Coefficients" } & \multirow{3}{*}{$t$} & \multirow{3}{*}{ Sig. } \\
\hline & & \multicolumn{2}{|c|}{ Unstandardized Coefficients } & \multirow{2}{*}{$\begin{array}{c}\begin{array}{c}\text { Standardized } \\
\text { Coefficients }\end{array} \\
\text { Beta }\end{array}$} & & \\
\hline & & B & Std. Error & & & \\
\hline & (Constant) & .119 & .058 & & 2.060 & .042 \\
\hline 1 & $\mathrm{x} 1$ & .626 & .032 & .871 & 19.340 & .000 \\
\hline & $\times 2$ & .050 & .073 & .061 & 1.349 & .001 \\
\hline
\end{tabular}

1. Variabel Pendapatan (X1)

Dari table diatas dapat dilihat bahwa nilai t hitung untuk (X1) Pendapatan sebesar 19,340 dengan nilai signifkansi 0,000 nilai signifikansi tersebut lebih kecil dari 0,05 dan nilai t hitung untuk pendapatan $(\mathrm{X} 1)=19,340>$ dari t table 1,98099, maka H0 ditolak dan $\mathrm{Ha}$ diterima, artinya pendapatan berpengaruh signifikan terhadap Tingkat konsumsi (Y) 
2. Variabel Gaya hidup (X2)

Pada tabel diatas dapat dijelaskan bahwa nilai t hitung untuk (X2) Gaya hidup sebesar 1,349 dengan nilai signifkansi 0,001 nilai signifikansi tersebut lebih kecil dari 0,05 dan nilai t hitung untuk Gaya hidup $(\mathrm{X} 2)=1,349<$ dari $\mathrm{t}$ table $=1,98099$, maka Ho diterima dan Ha ditolak, artinya gaya hidup tidak berpengaruh terhadap Tingkat konsumsi (Y)

d. Koefisien Determinan

Tabel; 23. Koefisien Determinan (R2)

\begin{tabular}{|l|r|r|r|c|}
\hline Model & R & R Square & $\begin{array}{c}\text { Adjusted R } \\
\text { Square }\end{array}$ & $\begin{array}{l}\text { Std. Error of the } \\
\text { Estimate }\end{array}$ \\
\hline 1 & $.886^{2}$ & .785 & .781 & .19044 \\
\hline
\end{tabular}

a. Predictors: (Constant), $\mathrm{X} 2, \mathrm{X} 1$

Dari Kofisien Determinan (Adjusted $R$ square) menunjukan 0,781 atau $78 \%$ variasi pada variabel Tingkat konsumsi dapat dijelaskan oleh kedua variabel bebas ( Pendapatan dan Gaya Hidup), adapun sisanya sebesar $22 \%$, dapat diterangkan oleh variabel lain di luar dari penelitian ini.

\section{PENUTUP}

\section{Kesimpulan}

1. Pendapatan berpengaruh positif dan signifikan terhadap tingkat konsumsi mahasiswa Sekolah Sekolah Tinggi Ilmu Ekonomi Indragiri (STIE-I) Rengat Tahun akademik 2018-2019 semester VI.

2. Gaya hidup tidak berpengaruh dan tidak signifikan terhadap tingkat konsumsi mahasiswa Sekolah Sekolah Tinggi Ilmu Ekonomi Indragiri (STIE-I) Rengat Tahun akademik 2018-2019 semester VI.

3. Pendapatan dan gaya hidup, bersama-sama berpengaruh signifikan terhadap tingkat konsumsi mahasiswa Sekolah Sekolah Tinggi Ilmu Ekonomi Indragiri (STIE-I) Rengat Tahun akademik 2018-2019 semester VI. Selain itu dari hasil perhitungan diperoleh nilai koefisien determinasi (R2) sebesar 0,781 atau $78,99 \%$. Nilai tersebut menunjukkan bahwa $78, \%$ tingkat konsumsi dipengaruhi oleh pendapatan dan gaya hidup. Dan $22 \%$ sisanya dapat dipengaruhi oleh variabel bebas lain yang tidak diteliti dalam penelitian ini.

\section{Saran}

1. Mahasiswa harus lebih bijaksana agar tidak menjadi pelaku konsumtif guna memanfaatkan pendapatan yang dimiliki.

2. Mahasiswa harus bisa mengatur pengeluaran untuk di konsumsi dalam hal gaya hidup. khususnya pada mahasiswa yang cenderung gaya hidupnya tinggi, Karena apabila menuruti gaya hidup maka akan lebih cenderung konsumtif.

3. Dari hasil penelitian ada variabel bebas lain yang tidak diteliti dalam penelitian ini, Maka saran yang dapat diberikan kepada peneliti selanjutnya 
yaitu perlu menambah variable lain selain dari ketiga variabel bebas yang digunakan dalam penelitian ini.

\section{REFERENCE}

Angga Sandy Susanto. 2013. Membuat Segmentasi Berdasarkan Life Style (Gaya Hidup), Jurnal JIBEKA, Vol. 7 No. 2 Agustus 2013, Hal. 1-6

James F.Engel \& Roger D.Blackwell \& Paul W.Miniard,F.X.Budiyanto. 2015.

Perilaku Konsumen. Binarupa Aksara. Jakarta

Kotler, Philip dan Gary Armstrong. 2008. Prinsip-Prinsip Pemasaran, Edisi 12. Jakarta: Erlangga

Lia Amaliawiati dan Asfia Murni. 2014. Ekonomika Mikro. Bandung: PT Refika Aditama

Mahyu Danil. 2013. Pengaruh Pendapatan terhadap Tingkat Konsumsi pada Pegawai Negeri Sipil di Kantor Bupati Kabupaten Bireuen, Jurnal

Mankiw, 2013. Pengantar Ekonomi Makro, Jakarta: Salemba Empat.

Muhamad Abdul Halim. 2012. Teori Ekonomika, Edisi 1. Jakarta: Jelajah Nusa

Pratiwi, G. E. 2014, Perilaku Konsumtif Dan Bentuk Gaya Hidup, Universitas Brawijaya Malang, November 2014, pp 17-18

Ristiayanti Prasetijo dan John J.O.I Ihalauw. 2006. Perilaku Konsumen. Yogyakarta: Andi Offset

Sadono Sukirno. 1999. Pengantar Teori Makroekonomi. Jakarta: PT Raja Grafindo Persada Edisi 17. Jakarta: PT Media Global Edukasi

Suherman Rosyidi. 2011. Pengantar Teori Ekonomi. Jakarta: PT Rajagrafindo Persada

Sukari, dkk, 2013. Perilaku Konsumtif Siswa SMA di Daerah Istimewa Y ogyakarta. Yogyakarta: BPNB

Suparmoko, M. 2011. Teori Ekonomi Mikro. Yogyakarta: BPFE

Sutanti. 2011. Analisis Konsumsi Masyarakat Propinsi Sumatera Utara. Tesis. Medan: Universitas Negeri Medan.

Tobing, Denova RL. (2015) Analisis Hubungan Antara Pendapatan dengan Perilaku Konsumsi Mahasiswa ( Studi Kasus Pada Mahasiswa Fakultas Ekonomi dan Bisnis Universitas Brawijaya) Jurnal Ilmiah. Malang. Universitas Brawijaya.

Ujang Sumarwan. 2011. Perilaku Konsumen, Edisi 2. Bogor: Ghalia Indonesia 